\title{
A!
}

This is an electronic reprint of the original article.

This reprint may differ from the original in pagination and typographic detail.

Shen, Leiting; Li, Xiaobin; Zhou, Qiusheng; Peng, Zhihong; Liu, Guihua; Qi, Tiangui; Taskinen, Pekka

Wolframite Conversion in Treating a Mixed Wolframite-Scheelite Concentrate by Sulfuric Acid

Published in:

JOM

DOI:

10.1007/s11837-017-2691-1

Published: 01/02/2018

Document Version

Peer reviewed version

Published under the following license:

Unspecified

Please cite the original version:

Shen, L., Li, X., Zhou, Q., Peng, Z., Liu, G., Qi, T., \& Taskinen, P. (2018). Wolframite Conversion in Treating a Mixed Wolframite-Scheelite Concentrate by Sulfuric Acid. JOM, 7O(2), 161-167. https://doi.org/10.1007/s11837017-2691-1

This material is protected by copyright and other intellectual property rights, and duplication or sale of all or part of any of the repository collections is not permitted, except that material may be duplicated by you for your research use or educational purposes in electronic or print form. You must obtain permission for any other use. Electronic or print copies may not be offered, whether for sale or otherwise to anyone who is not an authorised user. 


\title{
Wolframite conversion in treating a mixed wolframite-scheelite concentrate by
}

\section{sulfuric acid}

\author{
LEITING SHEN ${ }^{1,2}$, XIAOBIN LI $^{1,3}$, QIUSHENG ZHOU ${ }^{1}$, ZHIHONG PENG ${ }^{1}$, GUIHUA LIU ${ }^{1}$, \\ TIANGUI QI $^{1}$, PEKKA TASKINEN $^{2}$
}

1.-Central South University, School of Metallurgy and Environment, Changsha 410083, China.

2.-Aalto University, School of Chemical Engineering, Metallurgical Thermodynamics and Modeling Research Group, Espoo 02150, Finland.

3.—e-mail: x.b.li@csu.edu.cn

Complete wolframite conversion in sulfuric acid is significant for expanding the applicability of the sulfuric acid method for producing ammonium paratungstate. In this paper, the conversion of wolframite in treating a mixed wolframite-scheelite concentrate by sulfuric acid was studied systematically. The results show that the conversion of wolframite in sulfuric acid is more difficult than that of scheelite, requiring rigorous reaction conditions. A solid $\mathrm{H}_{2} \mathrm{WO}_{4}$ layer forms on the surfaces of the wolframite particles and becomes denser with increasing $\mathrm{H}_{2} \mathrm{SO}_{4}$ concentration, thus hindering the conversion. Furthermore, the difficulty in wolframite conversion can be mainly attributed to the accumulation of $\mathrm{Fe}^{2+}$ (and/or $\mathrm{Mn}^{2+}$ ) in the $\mathrm{H}_{2} \mathrm{SO}_{4}$ solution, which can be solved by reducing $\mathrm{Fe}^{2+}\left(\right.$ and/or $\mathrm{Mn}^{2+}$ ) concentration through oxidization and/or a two-stage process. Additionally, the solid converted product of the mixed wolframite-scheelite concentrate has an excellent leachability of tungsten in an aqueous ammonium carbonate solution at ambient temperature, with approximately $99 \% \mathrm{WO}_{3}$ recovery. This work presents a route for manufacturing ammonium paratungstate by treating the mixed concentrate in sulfuric acid followed by leaching in ammonium carbonate solution.

\section{INTRODUCTION}

Tungsten, a strategically rare metal, is steadily increasing in demand for various high-tech applications, due to its remarkable physical and chemical properties. ${ }^{1}$ It is widely used in hard materials, high temperature technology, and communication technologies, especially in armament and aero-space industries. ${ }^{2}$ Ammonium tungstate, as the main intermediate product in industrial tungsten extraction, is usually obtained by treating wolframite $\left((\mathrm{Fe}, \mathrm{Mn}) \mathrm{WO}_{4}\right)$, scheelite $\left(\mathrm{CaWO}_{4}\right)$, and mixed wolframite-scheelite concentrates by either caustic soda or hydrochloric acid. ${ }^{3}$

For treating wolframite, caustic digestion is employed to produce soluble sodium tungstate and 
insoluble iron or manganese hydroxide at either atmospheric pressure (348-418 K) in $\mathrm{NaOH}$ solutions $(\geq 10 \mathrm{~mol} / \mathrm{L})$ or at a high pressure $(408-528 \mathrm{~K})$ in $\mathrm{NaOH}$ solutions $(1.25-3.75 \mathrm{~mol} / \mathrm{L}) .{ }^{4} \mathrm{In}$ cases where the tungsten concentrate contains scheelite, a great amount of $\mathrm{Na}_{2} \mathrm{CO}_{3}$ should be added in the leaching system..$^{5}$ It should be noted that a large excess of reagents are required in leaching tungsten concentrates, raising questions of cost and the environment due to the difficulty in recycling. ${ }^{2}$ Additionally, subsequent solvent extraction or ion exchange process used to convert $\mathrm{Na}_{2} \mathrm{WO}_{4}$ to $\left(\mathrm{NH}_{4}\right)_{2} \mathrm{WO}_{4}$ consumes large quantities of acid to acidify the $\mathrm{Na}_{2} \mathrm{WO}_{4}$ solution or a large amount of water to dilute the leaching solution. ${ }^{6}$

As treating tungsten concentrates by acidic media can avoid discharging large amounts of sodium salts, some researchers have used chelates or phosphates to produce soluble tungsten compounds. Potashnikov et al. ${ }^{7}$ and Kalpakli et al. ${ }^{8}$ treated scheelite with oxalic acid to form water-soluble hydrogen aqua oxalato tungstate $\left(\mathrm{H}_{2}\left[\mathrm{WO}_{3}\left(\mathrm{C}_{2} \mathrm{O}_{4}\right) \mathrm{H}_{2} \mathrm{O}\right]\right)$. Hydrochloric or sulfuric acid in the presence of phosphorus has been employed in decomposing scheelite to 12-tungstophosphoric heteropoly acid $\left(\mathrm{H}_{3} \mathrm{PW}_{12} \mathrm{O}_{40}\right) .{ }^{9-11}$ On the other hand, hydrochloric acid ${ }^{12}$ or nitric acid ${ }^{13}$ has been used to attack synthetic scheelite-forming soluble metatungstates. These soluble tungsten compounds can subsequently follow the route of ammonium paratungstate production.

However, the high volatilization of hydrochloric acid or nitric acid results in heavy environmental stress and equipment corrosion, so sulfuric acid is an appropriate reagent for decomposing tungsten concentrates. Forward and Vizsolyi ${ }^{14}$ proposed a process in which calcium-containing tungsten concentrates were treated with sulfuric acid to form insoluble tungstic acid, followed by the separation of insoluble $\mathrm{H}_{2} \mathrm{WO}_{4}$ and $\mathrm{CaSO}_{4} \cdot \mathrm{nH}_{2} \mathrm{O}$ using dihydric or polyhydric aliphatic alcohol as the lixiviant. $\mathrm{Li}$ et al. ${ }^{15}$ systematically studied scheelite concentrate conversion in sulfuric acid, and examined the performance of separation of $\mathrm{H}_{2} \mathrm{WO}_{4}$ and $\mathrm{CaSO}_{4} \cdot \mathrm{nH}_{2} \mathrm{O}$ in an aqueous ammonium carbonate solution at ambient temperature, indicating that the sulfuric acid decomposing-ammonium carbonate leaching is a promising method.

Though the sulfuric acid method can theoretically decompose wolframite, there is limited literature available. Zelikman et al. ${ }^{16}$ pointed out that only a low degree of decomposition was achieved in sulfuric acid treating wolframite under conventional conditions, but that mechanical activation could significantly promote this process due to deep structural transformation in the wolframite mineral. $\mathrm{Xie}^{17}$ considered that wolframite decomposition in sulfuric acid solutions was determined by dynamic 
factors. However, neither Zelikman et al. ${ }^{16}$ nor Xie ${ }^{17}$ explained the detailed mechanism of decomposing wolframite in $\mathrm{H}_{2} \mathrm{SO}_{4}$ solutions.

Therefore, this paper focuses on clarifying the conversion behavior of wolframite in treating a mixed concentrate with sulfuric acid, and thus attempts to reveal the mechanism of wolframite conversion. In addition, the leachability of tungsten from the solid converted products was examined in aqueous ammonium carbonate solutions at ambient temperature. This work is beneficial for developing a cleaner technique of manufacturing ammonium paratungstate.

\section{EXPERIMENTAL}

\section{Materials}

All reagents, including $\mathrm{H}_{2} \mathrm{SO}_{4}, \mathrm{HNO}_{3}$, and $\left(\mathrm{NH}_{4}\right)_{2} \mathrm{CO}_{3}$, were analytically pure materials and supplied by Sinopharm Chemical Reagent. The initial tungsten concentrate (its chemical composition and XRD pattern are shown in supplementary Table SI and Fig. S1, respectively) used in this work was provided by Jiangxi Rare Metals Tungsten Holdings Group. The original tungsten concentrate was dried in an oven, and ground by a vibrating mill (FM-1, China) to a particle size $-150 \mu \mathrm{m}$.

Concentrates with different particle sizes were obtained by additional wet-grinding for different times, and their particle size distributions were measured by a Mastersizer 2000 (Malvern, UK) laser diffraction device.

\section{Procedures and Measurement}

Amounts of $90 \mathrm{~mL}$ sulfuric acid solution and $30 \mathrm{~g}$ tungsten concentrate (the liquid-solid ratio was $3 \mathrm{~mL} / \mathrm{g}$ ) were added to a $250-\mathrm{mL}$ three-neck round-bottom flask immersed in a thermostatic glycerol bath with an electronic temperature controller $( \pm 1 \mathrm{~K})$. The slurry was agitated by a polytetrafluoroethylene coated agitator (diameter $65 \mathrm{~mm}$, width $12 \mathrm{~mm}$ ) with a certain stirring speed at a preset temperature for a designed duration. The resulting slurry was then filtered and the filter cake obtained was washed using deionized water and dried in an oven at $363 \mathrm{~K}$ for $12 \mathrm{~h}$ to obtain the solid converted product. It should be noted that the free $\mathrm{H}_{2} \mathrm{SO}_{4}$ concentration (excessive sulfuric acid) in each experiment can be determined by the initial $\mathrm{H}_{2} \mathrm{SO}_{4}$ concentration and the stoichiometric consumption by $(\mathrm{Ca}, \mathrm{Fe}, \mathrm{Mn}) \mathrm{WO}_{4}$.

The phase analyses were performed by a X-ray diffractometer (D8-Advance; Bruker) using a Cu$\mathrm{K} \alpha$ with $0.0085^{\circ}$ step size at a scan rate of $1^{\circ} \cdot \mathrm{min}^{-1}$. The phase fractions of the solid converted products $(Y)$, only taking in account the tungsten-containing species, were calculated semi-quantitatively by the 
relative intensity ratio method with less than $5 \%$ error range $;{ }^{18}$ the details for data processing were described in our previous work ${ }^{15,19}$. The conversion ratios ( $\eta$ ) of $\mathrm{CaWO}_{4}$ and $(\mathrm{Fe}, \mathrm{Mn}) \mathrm{WO}_{4}$ to $\mathrm{H}_{2} \mathrm{WO}_{4}$ were thus determined by Eqs. 1-4, where $\mathrm{FeWO}_{4}$ involves ( $\left.\mathrm{Fe}, \mathrm{Mn}\right) \mathrm{WO}_{4}$.

$Y\left(\mathrm{CaWO}_{4}\right)(\%)=\left(\frac{\frac{X_{\mathrm{CaWO}_{4}}}{M_{\mathrm{CaWO}}}}{\frac{\overline{\mathrm{CaWO}}_{\mathrm{CaW}}}{\overline{\mathrm{CaWO}}_{4}}+\frac{X_{\mathrm{FeWO}}}{M_{\mathrm{FeWO}}}+\frac{X_{\mathrm{H}_{2} \mathrm{WO}_{4}}}{M_{\mathrm{H}_{2} \mathrm{WO}_{4}}}}\right) \times 100$

$Y\left(\mathrm{FeWO}_{4}\right)(\%)=\left(\frac{\frac{X_{\mathrm{FeWO}_{4}}}{M_{\mathrm{FeWO}}}}{\frac{X_{\mathrm{CaWO}_{4}}}{M_{\mathrm{CaWO}}}+\frac{X_{\mathrm{FeWO}}}{M_{\mathrm{FeWO}}}+\frac{X_{\mathrm{H}_{2} \mathrm{WO}_{4}}}{M_{\mathrm{H}_{2} \mathrm{WO}_{4}}}}\right) \times 100$

$\eta\left(\mathrm{CaWO}_{4}\right)(\%)=\left(1-\frac{Y\left(\mathrm{CaWO}_{4}\right)}{Y_{0}\left(\mathrm{CaWO}_{4}\right)}\right) \times 100$

$\eta\left(\mathrm{FeWO}_{4}\right)(\%)=\left(1-\frac{Y\left(\mathrm{FeWO}_{4}\right)}{Y_{0}\left(\mathrm{FeWO}_{4}\right)}\right) \times 100$

where $Y_{0}\left(\mathrm{CaWO}_{4}\right)$ and $Y_{0}\left(\mathrm{FeWO}_{4}\right)$ are the mole fractions of $\mathrm{CaWO}_{4}$ and $\mathrm{FeWO}_{4}$ in the mixed tungsten concentrate, $29.1 \%$ and $70.9 \%$, respectively; $Y\left(\mathrm{CaWO}_{4}\right)$ and $Y\left(\mathrm{FeWO}_{4}\right)$ are the mole fractions of $\mathrm{CaWO}_{4}$, and $\mathrm{FeWO}_{4}$ in the solid converted product; $X_{\mathrm{CaWO}_{4}}, X_{\mathrm{FeWO}_{4}}$ and $X_{\mathrm{H}_{2} \mathrm{WO}_{4}}$ are the mass fractions of $\mathrm{CaWO}_{4}, \mathrm{FeWO}_{4}$ and $\mathrm{H}_{2} \mathrm{WO}_{4}$ in the mixed tungsten concentrate; $M_{\mathrm{FeWO}_{4}}$, $M_{\mathrm{CaWO}_{4}}$ and $M_{\mathrm{H}_{2} \mathrm{WO}_{4}}$ are the molar masses of $\mathrm{FeWO}_{4}, \mathrm{CaWO}_{4}$, and $\mathrm{H}_{2} \mathrm{WO}_{4}$, respectively; and $\eta\left(\mathrm{CaWO}_{4}\right)$ and $\eta\left(\mathrm{FeWO}_{4}\right)$ are the conversion ratios of $\mathrm{CaWO}_{4}$ and $\mathrm{FeWO}_{4}$ to $\mathrm{H}_{2} \mathrm{WO}_{4}$, respectively;

Scanning electron microscope (Quanta 650, FEI) and energy dispersive spectrometer (Quantax 200 , Bruker) were used to investigate the morphologies and element distributions of the solid converted products. Additionally, the tungsten leachability of the solid converted product was examined in an aqueous ammonium carbonate solution, followed by determining the $\mathrm{WO}_{3}$ content of the leaching residue using the thiocyanate method ${ }^{20}$.

\section{RESULTS AND DISCUSSION}

\section{Conversion experiments}

First, the effect of stirring speed on the conversion ratio of tungsten concentrate was examined. The results in Fig. 1(a) indicate that the stirring speed has a small effect on the conversion of either $\mathrm{CaWO}_{4}$ or $(\mathrm{Fe}, \mathrm{Mn}) \mathrm{WO}_{4}$, especially with stirring speeds over $300 \mathrm{rpm}$. This suggests that the conversion is not determined by external diffusion. The slight decrease of the conversion ratio at 600 rpm was caused by the slight adhesion of tungsten concentrate to the flask wall. Therefore, stirring speed of $300 \mathrm{rpm}$ was adopted in the other experiments.

According to our previous research ${ }^{15}$, the $\mathrm{H}_{2} \mathrm{SO}_{4}$ concentration markedly influences the 
conversion of tungsten concentrate. As shown in Fig. 1(b), the conversion ratios of both $\mathrm{CaWO}_{4}$ and (Fe, $\mathrm{Mn}) \mathrm{WO}_{4}$ rise remarkably with increasing $\mathrm{H}_{2} \mathrm{SO}_{4}$ concentration, but $\mathrm{CaWO}_{4}$ can be converted almost completely with $\mathrm{H}_{2} \mathrm{SO}_{4}$ concentrations above $450 \mathrm{~g} / \mathrm{L}$. The maximum conversion ratio of (Fe,Mn) $\mathrm{WO}_{4}$ was only about $63 \%$, which indicates that $\mathrm{CaWO}_{4}$ reacts with $\mathrm{H}_{2} \mathrm{SO}_{4}$ more readily than $(\mathrm{Fe}, \mathrm{Mn}) \mathrm{WO}_{4}$. The SEM of the mixed wolframite-scheelite concentrate (see supplementary Fig. S4) indicates that wolframite and scheelite are mutually disseminated and most scheelite grains with a width of less than $20 \mu \mathrm{m}$ are much finer than the wolframite grains. This may be one reason why scheelite converts much more quickly than wolframite in the mixed concentrate.

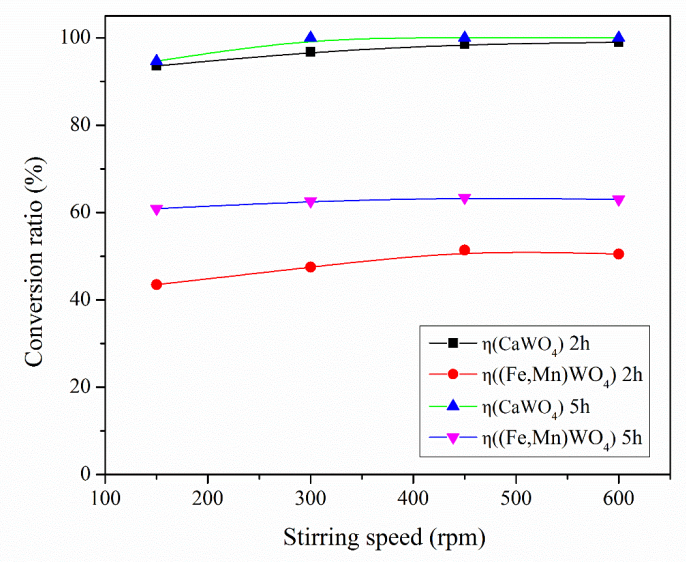

(a) Stirring speed $\left(363 \mathrm{~K}, 3 \mathrm{~mL} / \mathrm{g}, 450 \mathrm{~g} / \mathrm{L} \mathrm{H}_{2} \mathrm{SO}_{4},-150 \mu \mathrm{m}\right)$

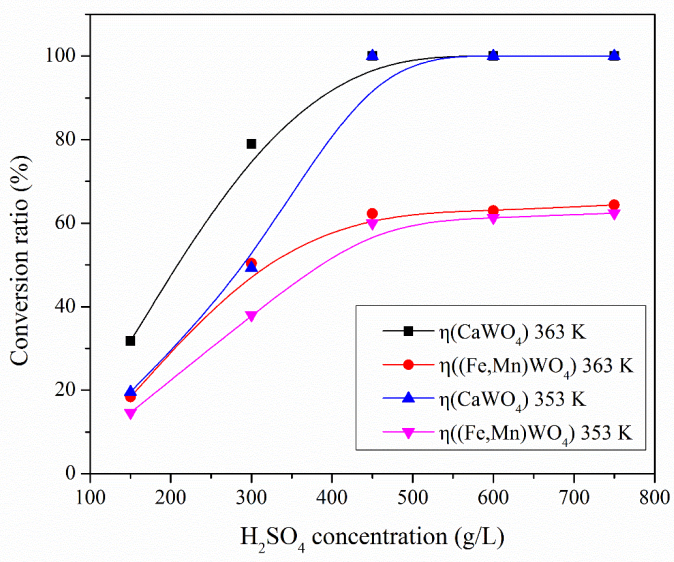

(b) $\mathrm{H}_{2} \mathrm{SO}_{4}$ concentration $(3 \mathrm{~mL} / \mathrm{g}, 5 \mathrm{~h}, 300 \mathrm{rpm},-150 \mu \mathrm{m})$ 


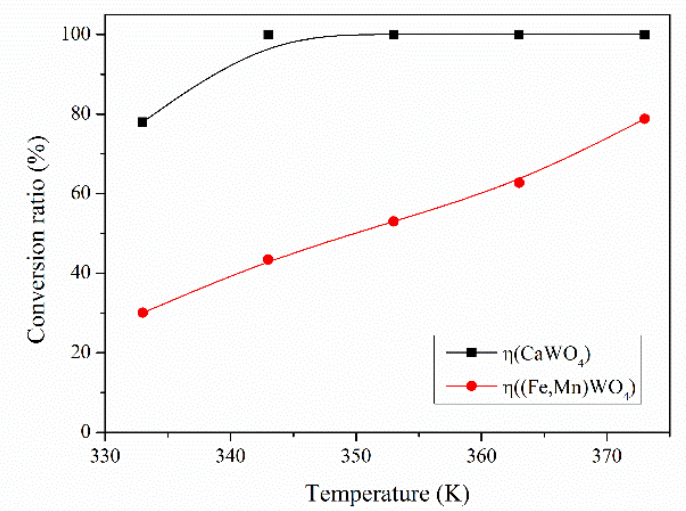

(c) Temperature ( $\left.450 \mathrm{~g} / \mathrm{L} \mathrm{H}_{2} \mathrm{SO}_{4}, 3 \mathrm{~mL} / \mathrm{g}, 5 \mathrm{~h}, 300 \mathrm{rpm},-150 \mu \mathrm{m}\right)$

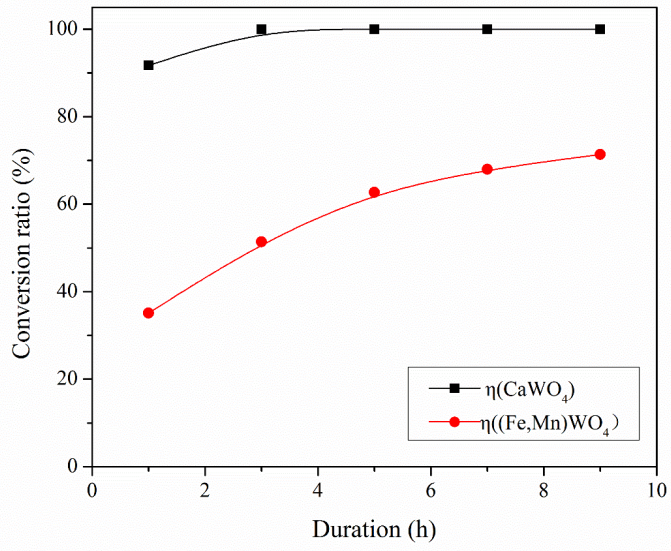

(d) Duration $\left(363 \mathrm{~K}, 3 \mathrm{~mL} / \mathrm{g}, 450 \mathrm{~g} / \mathrm{L} \mathrm{H}_{2} \mathrm{SO}_{4}, 300 \mathrm{rpm},-150 \mu \mathrm{m}\right)$

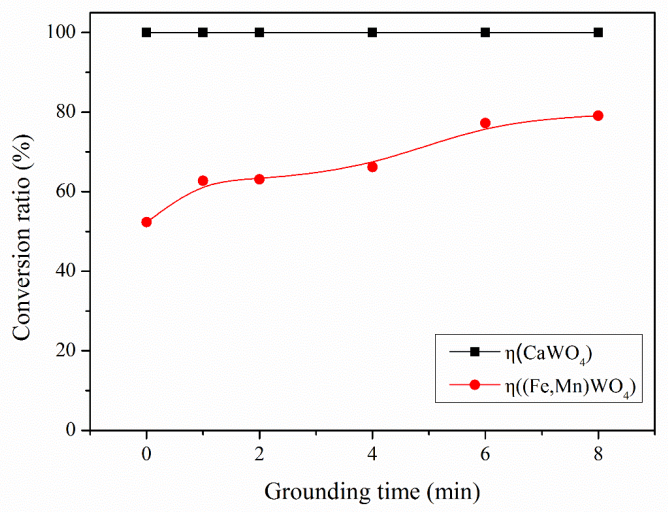

(e) Particle size ( $363 \mathrm{~K}, 3 \mathrm{~mL} / \mathrm{g}, 450 \mathrm{~g} / \mathrm{L} \mathrm{H}_{2} \mathrm{SO}_{4}, 300 \mathrm{rpm}, 5 \mathrm{~h}$ )

Fig. 1. Effect of experimental conditions on conversion ratios of scheelite and wolframite.

Conventionally, temperature and duration play important roles in the conversion. As illustrated in Fig. 1(c), increasing temperature remarkably promotes the conversion of wolframite in $\mathrm{H}_{2} \mathrm{SO}_{4}$ solutions, but it does not convert completely, its maximum conversion ratio was only $78.8 \%$ even at 
$373 \mathrm{~K}$. The acceleration of $(\mathrm{Fe}, \mathrm{Mn}) \mathrm{WO}_{4}$ conversion along with temperature may be attributed to the intensification of dynamic processes. With respect to reaction time, the conversion ratio of wolframite slowly increases with time, and it reaches only about $68.0 \%$ even after $9 \mathrm{~h}$ (Fig. 1(d)).

In order to study the effect of particle size, the tungsten concentrates with different particle sizes were obtained by wet-grinding in vibrating mill for different time, and the particle size decreases with prolonging grinding time (see supplementary Fig. S7). Fig. 1(e) represents the dependence of conversion ratio on grinding time, which indicates that the conversion ratio of wolframite rises with the particle size reduction, especially with the elimination of coarse particles $(>20 \mu \mathrm{m})$. Hence, the conversion of wolframite in $\mathrm{H}_{2} \mathrm{SO}_{4}$ solutions is evidently determined by internal diffusion in the concentrate particles and/or by surface reaction.

It can be expected that a prolonged reaction time favors the conversion of wolframite, and thus the conversion experiment of tungsten concentrate ground for 5 min was conducted in $450 \mathrm{~g} / \mathrm{L} \mathrm{H}_{2} \mathrm{SO}_{4}$ solution at $363 \mathrm{~K}$ for $24 \mathrm{~h}$. No characteristic diffraction peaks of $(\mathrm{Fe}, \mathrm{Mn}) \mathrm{WO}_{4}$ were observed in the XRD pattern of the solid converted product (see supplementary Fig. S9), indicating the complete conversion of wolframite.

\section{Conversion mechanism}

As discussed above, the complete conversion of wolframite in the mixed concentrate by $\mathrm{H}_{2} \mathrm{SO}_{4}$ solution can be achieved under much more rigorous conditions than those for scheelite, requiring concentrated sulfuric acid $(\geq 450 \mathrm{~g} / \mathrm{L})$, high temperature $(\geq 363 \mathrm{~K})$, long reaction time $(\sim 24 \mathrm{~h})$, and small particle size $(<20 \mu \mathrm{m})$. In order to optimize the conversion, it is necessary to clarify the conversion mechanism of wolframite in $\mathrm{H}_{2} \mathrm{SO}_{4}$ solutions.

Figure 2 shows a SEM image of the solid converted product for the mixed wolframite-scheelite concentrate in $450 \mathrm{~g} / \mathrm{L} \mathrm{H}_{2} \mathrm{SO}_{4}$ solution, a product layer can be clearly observed coating the particles and forming a shrinking core of the unreacted mineral. Combining the backscattered electron image with EDS analyses (see supplementary Table SII), we found that the surface layer is principally made up of solid $\mathrm{H}_{2} \mathrm{WO}_{4}$, expectedly hindering the conversion of wolframite. 


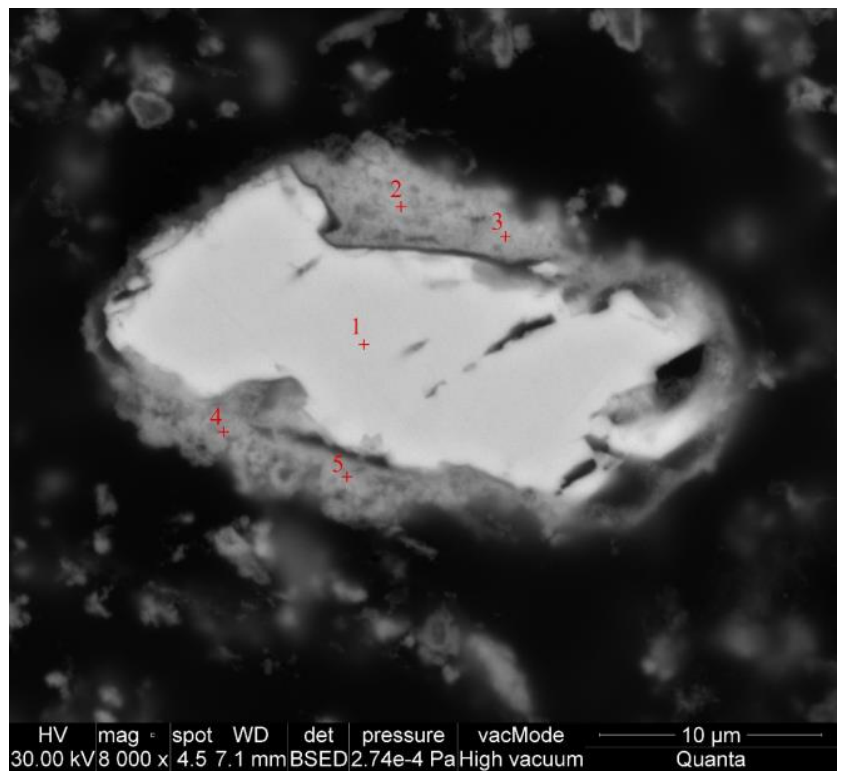

Fig. 2. A SEM image of the partially solid converted product $\left(363 \mathrm{~K}, 5 \mathrm{~h}, 3 \mathrm{~mL} / \mathrm{g}, 450 \mathrm{~g} / \mathrm{L} \mathrm{H}_{2} \mathrm{SO}_{4}, 300\right.$

$$
\text { rpm, } \left.-150 \mu \mathrm{m} .1:(\mathrm{Fe}, \mathrm{Mn}) \mathrm{WO}_{4} ; 2-5: \mathrm{H}_{2} \mathrm{WO}_{4}\right) \text {. }
$$

The effect of $\mathrm{H}_{2} \mathrm{SO}_{4}$ concentration on the layer growth during the wolframite conversion was studied and the results are shown in Fig. 3. The results clearly indicate that the product layer on the coarse particles of the unreacted mineral becomes denser with increasing $\mathrm{H}_{2} \mathrm{SO}_{4}$ concentration. The layer is nebulous in $150 \mathrm{~g} / \mathrm{L} \mathrm{H}_{2} \mathrm{SO}_{4}$, crystalline in $300 \mathrm{~g} / \mathrm{L} \mathrm{H}_{2} \mathrm{SO}_{4}$ and loose in $450 \mathrm{~g} / \mathrm{L} \mathrm{H}_{2} \mathrm{SO}_{4}$, and it ultimately becomes thin and dense in $750 \mathrm{~g} / \mathrm{L} \mathrm{H}_{2} \mathrm{SO}_{4}$. The dense layer formed slows down not only the reactants diffusing to the surface of the unreacted wolframite grains but also the reaction products migrating off, which can well explain the decreased conversion rates of the wolframite with high $\mathrm{H}_{2} \mathrm{SO}_{4}$ concentration (>400 g/L) as shown in Fig. 1(b).
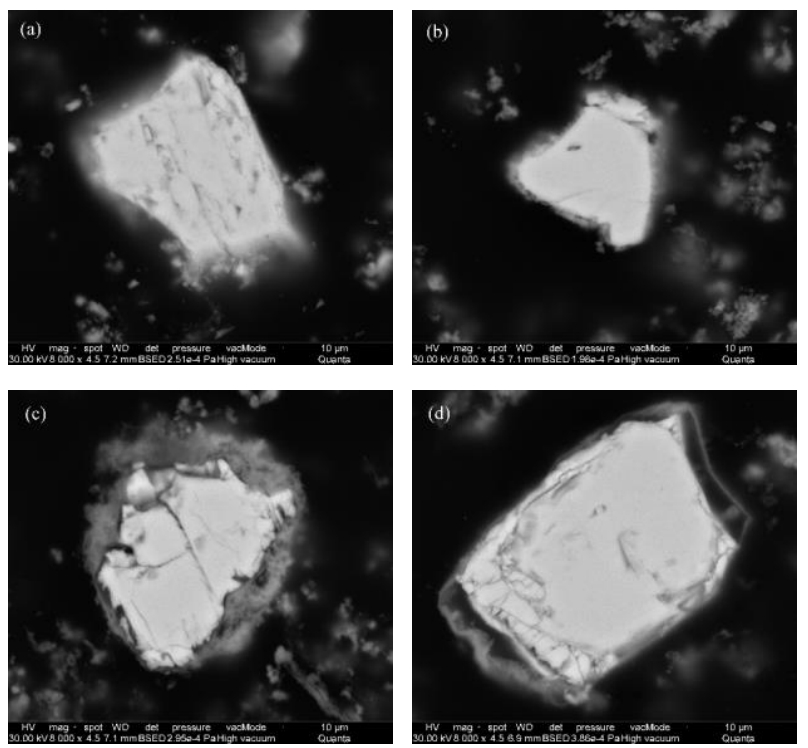
Fig. 3. SEM images of the solid converted products with different $\mathrm{H}_{2} \mathrm{SO}_{4}$ concentrations $(363 \mathrm{~K}, 5 \mathrm{~h}, 3$ mL/g, $300 \mathrm{rpm},-150 \mu \mathrm{m}, \mathrm{H}_{2} \mathrm{SO}_{4}$ concentration: (a) $150 \mathrm{~g} / \mathrm{L}$, (b) $300 \mathrm{~g} / \mathrm{L}$, (c) $450 \mathrm{~g} / \mathrm{L}$, and (d) $750 \mathrm{~g} / \mathrm{L}$ ).

Our previous research on the scheelite concentrate conversion in $\mathrm{H}_{2} \mathrm{SO}_{4}$ solutions ${ }^{15}$ indicated that the conversion ratio of scheelite decreases with $\mathrm{H}_{2} \mathrm{SO}_{4}$ concentration exceeding a certain value, differing from the wolframite conversion behavior depending on $\mathrm{H}_{2} \mathrm{SO}_{4}$ concentration (Fig. 1(b)). This difference can be explained in three ways.

Firstly, it can be attributed to their difference in thermodynamics of the conversion reactions, on which Martins has made meaningful research ${ }^{5}$. According to his research, the decomposition of scheelite and wolframite can be expressed as follows:

$$
\begin{aligned}
& \mathrm{H}_{2} \mathrm{SO}_{4}(\mathrm{aq})+\mathrm{CaWO}_{4}(\mathrm{~s}) \rightleftharpoons \mathrm{CaSO}_{4}(\mathrm{~s})+\mathrm{H}_{2} \mathrm{WO}_{4}(\mathrm{~s}) \\
& \mathrm{H}_{2} \mathrm{SO}_{4}(\mathrm{aq})+\mathrm{FeWO}_{4}(\mathrm{~s}) \rightleftharpoons \mathrm{FeSO}_{4}(\mathrm{aq})+\mathrm{H}_{2} \mathrm{WO}_{4}(\mathrm{~s}) \\
& \mathrm{H}_{2} \mathrm{SO}_{4}(\mathrm{aq})+\mathrm{MnWO}_{4}(\mathrm{~s}) \rightleftharpoons \mathrm{MnSO}_{4}(\mathrm{aq})+\mathrm{H}_{2} \mathrm{WO}_{4}(\mathrm{~s})
\end{aligned}
$$

In order to more intuitively discuss the conversions, a thermodynamic calculation for the conversions of tungsten-containing minerals in $\mathrm{H}_{2} \mathrm{SO}_{4}$ was conducted with HSC $9.0^{21}$, in which all the thermodynamic data except that of $\mathrm{MnWO}_{4}$ are fairly close to Martins's ${ }^{5}$. The thermodynamic data of $\mathrm{MnWO}_{4}\left(G_{298 \mathrm{~K}}^{\mathrm{o}}=-1206.08 \mathrm{~kJ} \cdot \mathrm{mol}^{-1}\right)$ used in this work was taken from the database in HSC $9.0^{21}$ and is almost the same to Horner's ${ }^{22}$, while Martins ${ }^{5}$ reported the data as $-1172.48 \mathrm{~kJ} \cdot \mathrm{mol}^{-1}$. As shown in Fig. 4, raising the temperature favors the conversion of $\mathrm{CaWO}_{4}$ thermodynamically, while the standard Gibbs free energy changes of $\mathrm{FeWO}_{4}$ and $\mathrm{MnWO}_{4}$ conversions increase slightly but keep a relatively large negative value with increasing temperature. Taking into account the kinetics, increasing the temperature benefits the conversion of the mixed concentrate in $\mathrm{H}_{2} \mathrm{SO}_{4}$ solution, in accordance with the experimental result in Fig. 1(c). In addition, the preferential conversion order is thermodynamically $\mathrm{CaWO}_{4}>\mathrm{MnWO}_{4}>$ $\mathrm{FeWO}_{4}$ at $>298 \mathrm{~K}$, which is in good agreement with the experimental conversion result. For instance, the conversion of the scheelite in the mixed concentrate is complete in $450 \mathrm{~g} / \mathrm{L} \mathrm{H}_{2} \mathrm{SO}_{4}$ at $363 \mathrm{~K}$ for $5 \mathrm{~h}$, while the conversion ratio of wolframite is only about $62 \%$ with the Fe/Mn mass ratio increasing from 2.585 in the mixed concentrate to 3.041 in the converted product (see supplementary Table SIII). 


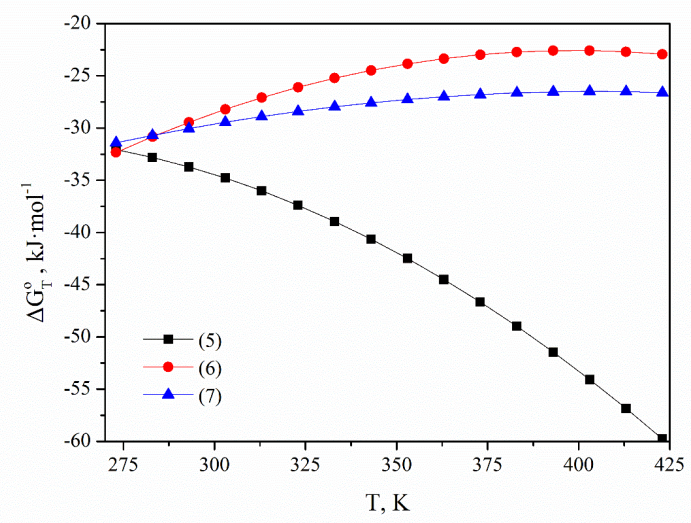

Fig. 4. Standard Gibbs energy changes of conversion reactions (5)-(7) versus temperature (HSC 9.0 database $\left.^{21}\right)$.

Secondly, the concentrations of cations in the solution will influence the conversion. During the conversion, the $\mathrm{Ca}^{2+}$ concentration in the solution is very low due to forming sparingly soluble $\mathrm{CaSO}_{4}$ $\left(\mathrm{Ksp}=10^{-4.38}\right)^{23}$, while the concentrations of $\mathrm{Fe}^{2+}$ and $\mathrm{Mn}^{2+}$ increase. Therefore, the accumulation of $\mathrm{Fe}^{2+}$ and $\mathrm{Mn}^{2+}$ in the solution will resist reactions (6) and (7), progressing towards the right according to Le Chatelier's principle. The influence of $\mathrm{Fe}^{2+}$ on the wolframite conversion was confirmed in three ways, i.e., two-stage conversion (substituting fresh $\mathrm{H}_{2} \mathrm{SO}_{4}$ solution for part of conversion solution), oxidization of $\mathrm{Fe}^{2+}$ in the solution with adding $\mathrm{HNO}_{3}$, and increase of $\mathrm{Fe}^{2+}$ concentration with adding $\mathrm{FeSO}_{4}$. The results show that reducing the $\mathrm{Fe}^{2+}$ concentration in the former two ways can realize the complete conversion of the wolframite under optimized conditions (see supplementary Fig. S10), whereas increasing $\mathrm{Fe}^{2+}$ concentration in the third way remarkably decreases the conversion ratio (see supplementary Fig. S11).

Thirdly, the product layer of $\mathrm{H}_{2} \mathrm{WO}_{4}$ retards the conversion of the wolframite, which was proved by the grinding while converting experiment, combined with the above-mentioned results of the dependence of the conversion ratio on the concentrate particle size (Fig. 1(e)). The wolframite conversion ratios (see supplementary Fig. S12) reach $92 \%$ and $~ 93 \%$ through wet-grinding the concentrate for 20 min (particle size $\mathrm{d}(90)$ reduction to $13.3 \mu \mathrm{m}$ ) and grinding while converting, respectively. The incomplete conversion means that the product layer is not the decisive factor although it has a negative influence on the conversion.

In summary, the conversion of wolframite in the mixed concentrate is mainly dominated by thermodynamics, in which the accumulation of the corresponding metal cation in the solution plays the 
most important role.

\section{Leaching test}

The solid converted product is a mixture of tungstic acid and calcium sulfate for the mixed wolframite-scheelite concentrate. To separate $\mathrm{H}_{2} \mathrm{WO}_{4}$ from $\mathrm{CaSO}_{4}, 25 \mathrm{~g}$ well-converted dry product was preliminarily examined in $100 \mathrm{~mL} 400 \mathrm{~g} / \mathrm{L}$ ammonium carbonate solution at ambient temperature for 2 h.

The $\mathrm{WO}_{3}$ content in the obtained leaching residue was $3.85 \%$, with the calculated $\mathrm{WO}_{3}$ leaching efficiency of $98.86 \%$. XRD analysis of the leaching residue (see supplementary Fig. S13) indicates that calcium carbonate $\left(\mathrm{CaCO}_{3}\right)$ generated together with the unreacted gangue minerals is present in the leaching residue. These results indicate that ammonium carbonate solution may be employed for effectively recovering tungsten as ammonium paratungstate from the solid converted product under mild conditions.

\section{CONCLUSION}

(1) Concentrated sulfuric acid ( $\geq 450 \mathrm{~g} / \mathrm{L})$, high temperature $(\geq 363 \mathrm{~K})$, long reaction time ( $\geq 5 \mathrm{~h})$, small particle size $(<20 \mu \mathrm{m})$, and low concentration of $\mathrm{Fe}^{2+}\left(\right.$ and/or $\left.\mathrm{Mn}^{2+}\right)$ in the solution facilitate the conversion of wolframite to $\mathrm{H}_{2} \mathrm{WO}_{4}$ in treating mixed wolframite-scheelite concentrates with $\mathrm{H}_{2} \mathrm{SO}_{4}$ solutions.

(2) The conversions of tungsten minerals in $\mathrm{H}_{2} \mathrm{SO}_{4}$ solutions are preferentially in the order of $\mathrm{CaWO}_{4}>\mathrm{MnWO}_{4}>\mathrm{FeWO}_{4}$. The difficulty of wolframite conversion in $\mathrm{H}_{2} \mathrm{SO}_{4}$ solutions can be mainly attributed to the accumulation of $\mathrm{Fe}^{2+}\left(\right.$ and/or $\mathrm{Mn}^{2+}$ ) as well as the solid $\mathrm{H}_{2} \mathrm{WO}_{4}$ layer covering the wolframite particles.

(3) Tungsten in the solid converted product of a mixed wolframite-scheelite concentrate can be readily extracted by aqueous ammonium carbonate solutions to directly obtain an ammonium tungstate solution.

\section{ACKNOWLEDGMENTS}

This work is financially supported by the National Natural Science Foundation of China (No.51274243). 
1. D.H. Yang, R.R. Srivastava, M.S. Kim, D.D. Nam, J.C. Lee, T.H. Hai, Met. Mater. Int. 22 (5), 897 (2016).

2. E. Lassner, W. Schubert, E. Lüderitz, H.U. Wolf, Wiley-VCH Verlag GmbH \& Co. KGaA (2012) doi:10.1002/14356007.a27_229.

3. R.P.S. Gaur, JOM 58 (9), 45 (2006).

4. E. Lassner, Int. J. of Refract. Met. Hard Mater. 13 (1-3), 35 (1995).

5. J.I. Martins, Min. Proc. Ext. Met. Rev. 35(1), 23(2014).

6. K. Vadasdi, Int. J. of Refract. Met. Hard Mater. 13 (1), 45 (1995).

7. Y.M. Potashnikov, A.M. Gamol'skii, M.V. Mokhosoev, F.M. Zh. Neorg. Khim. 15 (2), 502 (1970).

8. A.O. Kalpakli, S. Ilhan, C. Kahruman, I. Yusufoglu, Hydrometallurgy 121-124, 7 (2012).

9. G.H. Xuin, D.Y. Yu, Y.-F. Su, Hydrometallurgy 16, 27 (1986).

10. S. Gurmen, S. Timur, C. Arslan, I. Duman, Hydrometallurgy 51, 227 (1999).

11. J.T. Li, Z.W. Zhao, Hydrometallurgy 163, 55 (2016).

12. J.I. Martins, A. Moreira, S.-C. Costa, Hydrometallurgy 70, 131 (2003).

13. J.I. Martins, Ind. Eng. Chem. Res. 42, 5031 (2003).

14. F.A. Forward, A.I. Vizsolyi, United States Patent, No. 3193347 (1965).

15. X.B. Li, L.T. Shen, Q.S. Zhou, Z.H. Peng, G.H. Liu, T.G. Qi, Hydrometallurgy 171, 106 (2017).

16. A.N. Zelikman, A.S. Medvedev, Z.O. Kadyrova, Izv. V.U.Z. Tsvetn. Metall. 3, 69 (1986). (in Russian).

17. H. Xie, The novel technology of extracting wolframite with sulfuric acid, (Changsha, Master of science thesis, Central South University, China 2011). (in Chinese).

18. S.S. Al-Jaroudi, A. Ul-Hamid, A.R.I. Mohammed, S. Saner, Powder Technol. 175 (3), 115 (2007).

19. X.B. Li, X.M. Xu, Q.S. Zhou, Z.H. Peng, G.H. Liu, T.G. Qi, et al., Int. J. Refract. Met. Hard Mater. 52, 151 (2015).

20. S.C. Srivastava, S.R. Bhaisare, D.N. Wagh, C.P.S. Iyer, Bull. Mater. Sci. 19, 331 (1996).

21. A. Roine, HSC Chemistry, vers. 9.0, Outotec Research Oy, Pori (Finland), Mar. 2016, http://www.outotec.com/products/digital-solutions/hsc-chemistry/.

22. C. Horner, Chemical Geology, 27, 85 (1979).

23. J.G. Speight, Lange's handbook of chemistry, 16th ed. (New York, NY: McGraw-Hill Book Co., 2005), Sec. one. 